\title{
Moral values and environmental responsibility for future generations: case study of Russia
}

\author{
Dina Kazantseva ${ }^{1, *}$, Elena Tkach $^{2}$, and Irina Sokolovskaya ${ }^{3}$ \\ ${ }^{1}$ Southern Federal University, 344006, Bolshaya Sadovaya st., 105/42, Rostov-on-Don, Russia \\ ${ }^{2}$ Pacific National University, Karl Marx Street, 68, 680013, Khabarovsk, Russia \\ ${ }^{3}$ Russian State Social University, 129226, Wilhelm Pik str., 4, p. 1, Moscow, Russia
}

\begin{abstract}
Annotation. Spiritual and moral values and motives are historically the basis of the mental matrix of the Russian citizen, determining the development and acting as a psychological coping mechanism in a crisis. In the modern world, it is spiritual values and motives that are being transformed. Mental protection of a personality based on the integrity of primal archetypes of the collective unconscious, creating mental traits and identity is interrupted, which leads to destructive changes, specifically, deprivation, alienation, deviance. In this regard, the purpose of the article is to identify the features of the transformation of spiritual and moral values of modern Russians. In the course of four sociological studies in 2007, 2009, 2010, 2019 in the regions of Russia, the values of schoolchildren (15-17 years), students (17-22 years), working youth (23-29 years) were studied. The research was based on personal, activity oriented, systemic and subjective approaches. It resulted in the consideration of the dynamics of personal values' changes from 2007 to 2019 , revealing the integrity of basic, spiritual, and moral values, which are fundamental for the personality formation of a Russian living in a particular historical and geographical environment.
\end{abstract}

\section{Introduction}

The sphere of values and motives is an intrapersonal central unit of a personality. Determining the worldview motives of a person's activity focus awakens motivated activity toward personal and social goals. Values and motives as dynamic personal formations provide stable development of all mental mechanisms of a personality, self-fulfillment of its potential, adaptation, and socialization. For thousands of years, each nation has developed its hierarchical system of values, which is responsible for providing psychological coping mechanisms for regulating the activities of individuals and society, in the light of specific natural and climatic conditions of life. The content-dynamic motive was influenced by values, determining the hierarchy and structure of the value system, the historical content, and the specific socio-economic conditions.

Russia was historically dominated by the spiritual and moral values system, which formed the core value preferences and created a high degree of stability of the personality in the face

${ }^{*}$ Corresponding author: $\underline{\text { iren3d } @ \text { yandex.ru }}$ 
of external pressure, allowing to navigate in a diverse world of values. The spiritual world through culture entered the space of a person's life, created the integrity of the emotional and sensual, intellectual and pragmatist spheres, became an individual and personal experience, which regulates the behavior.

The Slavophiles I.V. Kireevsky, A.S. Khomyakov, and the Nativists - N.E. Astafiev, N.Y. Danilevsky, F.M. Dostoevsky, A.A. Grigoriev, and N.N. Strakhov were the first to pay attention to the specificity of the national self-identity in 19th-century Russian philosophy. Spiritual culture, associated with the native nature and the value system developed by the individual, was described by philosophers of the XX century - Y.A. Zhdanov, G.D. Gachev, D.S. Likhachev, Y.M. Lotman as well as philosophers of the Russian abroad - N.A. Berdyaev, I.A. Ilyin, N.O. Lossky, etc.

A specific feature of nineteenth- and twentieth-century studies was the identification of the spiritual foundations of the national worldview as part of the structure of the national unity formed by the environment. The spiritual was described as a powerful regulator of people's life, a high ideal of sanctity and moral purity. Manifesting itself through the material, it was connected to it through a system of spiritual and moral values (kindness, compassion, mercy, faith, love, conscientiousness, patience, responsiveness, etc.).

Life motives, expressed in extra-situational and sustainable values, determined the ways of satisfying the needs and achieving the goals of the people, created a worldview system expressed in cultural codes. Motivational constructs, out of the plane of consciousness, the image of the subject's world, encouraged activity and determined its orientation. Values as motivational formations were investigated by B.S. Bratus, F.E. Vasilyuk, A.N. Leontiev, D.A. Leontiev, E.Y. Pyataeva, S.L. Rubinstein, and others.

At the edge of the XX-XXI centuries A.L. Venger, N.A. Karateeva, V.S. Malitsky, V.A. Shemchuk spoke of the people's spiritual culture, showing that at this stage of social development, there was "a gap" between scientific cognition of the universe structure and the spiritual world of an individual. Individual consciousness that previously had a triune value of Good, Beauty and Truth has gradually begun to disintegrate, losing the integrity of the worldview system. The authors noted, that for the development of the people, the preservation of an integral system of essential relations and the unity of material and spiritual culture, manifested in various forms of development of life (economic, political, social spheres) is needed.

The socio-economic conditions of the 21 st century have changed the standards, rules, and values of Russians' lives. The new value system has fundamentally disrupted the traditional regularity of life and has come into conflict with the traditional mechanisms, stereotypes, and regulations. The features of perception of new values in the Russian public consciousness and the possibilities of traditional values conversion to values of freedom, as well as the processes of socialization and personality characteristics change when changing the way of life started to be discussed in researches of B.V. Dubin, P.E. Kandel, V.V. Lapkin, V.A. Melyantseva, N.E. Pokrovsky, M.V. Pankina, Y.A. Plyais, T.Y. Timofeev.

However, the specific essence of spiritual and moral values serving as the basis of the national identity of Russians proved to be incompatible with the values of individualism, power, wealth, careerism, rationalism, freedom from one's relatives, etc. Years of transformation may have changed not only the structures of the national mentality consciousness but also its unconscious, primal structures. The transformation of mental features, the primal archetypes, could affect the mental make-up and identity of the people. In this regard, the need to identify the peculiarities of the transformation of spiritual and moral values of modern Russians has emerged. 


\section{Materials and methods}

The scientific literature analysis on the issue of studying human values and the influence of social changes on the process of spiritual development of an individual was the basis for conducting research. From 2007 to 2019 empirical studies were conducted to identify the peculiarities of spiritual and moral values transformation of the Russians. Comparative characterization of the results of the 2007 and 2009 survey of young people under the age of 30 in one of the regions of Russia and the results obtained in three regions of Russia in 2010 and 2019 was carried out.

In connection with the socio-economic changes in Russia that initiated the transformation of the spiritual and moral values since the beginning of the 1990s, the first stage included a theoretical analysis of the empirical studies of the ISI RAS, VCIOM, ROMIR, RSIS\&NP (1992-2005) that generally describe trends in the development of attitudes, beliefs, and values of the Soviet and post-Soviet society.

At the second stage, in June - July 2007 in Penza, an empirical study of personal spiritual and moral values transformation was carried out within the grant of the Russian Humanitarian Scientific Foundation 07-06-28607a/B in 2007-2008. "Transformational processes of the spiritual potential of a personality as a basis for successful socialization of the younger generation" [1]. The questionnaire containing the questions for the study of personal values was presented to the respondents. A total of 693 people were interviewed: 232 schoolchildren (15-17 years old), 244 students (17-22 years old), and 217 working youth (23-29 years old). There were $63.9 \%$ of women and $36.1 \%$ of men among the respondents. This allowed us to study the system of values that determines the formation of the personality living in a certain environment, its socialization, and adaptation opportunities.

The second sociological study was conducted in November-December 2009 in Penza. It was a preliminary version of a new project, which developed a large-scale sociological study in 2010 in three regions of Russia. The respondents answered the same questionnaire as in the study in 2007. A total of 325 people were questioned, including 103 schoolchildren (ages 15-17), 110 students (ages 17-22), and 112 working youth (ages 23-29). There were 52.5\% of women and $47.5 \%$ of men. This allowed us to compare the changes in the values system that occurred during the two years.

At the third stage in 2010, the scope of research was expanded to the Volga (Penza), Central (Moscow), and Southern (Rostov-on-Don) Federal Districts. The mass questionnaire survey was conducted from January 1, 2010, to January 31, 2010. The sample size was 1,320 male and female respondents under 30 years of age. Four age groups of youth were researched: 14-17 years old, 18-21 years old, 22-25 years old, and 26-29 years old. The preliminary study in 2009 and the scaled study in 2010 were carried out within the research "Intergenerational Transformation of Spiritual and Moral Potential of a Young Person in Modern Socio-Cultural Environment, as well as State Regulation of this Process to Ensure Sustainable Development of Modern Society in a Globalized Environment" within the Federal Target Program "Scientific and Scientific-Pedagogical Personnel of Modern Russia 2009-2013".

The main objective of the fourth phase was to conduct a survey in 2019, repeating the sociological survey of 2010. A mass questionnaire survey was conducted in the Volga (Penza), Central (Moscow), and South (Rostov-on-Don) federal districts from January 1, 2019 , to January 31,2019 . The sample size was 830 men and women under 30 years of age. Four age groups of young people were studied: 14-17 years old, 18-21 years old, 22-25 years old, and 26-29 years old.

The final stage was a comparative analysis of the results obtained from the empirical studies in 2007 and 2009 and the results of the studies in 2010 and 2019. The comparison of 
the studies allowed us to explore the dynamics of spiritual and moral values changes of modern youth from 2007 to 2019 .

The results of the study were considered and summarized for each age group. The dynamics of changes in the value systems (vital, social, moral, religious, political, aesthetic), spiritual and moral values (compassion, mercy, honesty, kindness, philanthropy, humanity, victimhood), and values associated with spiritual and moral ones that promote personal development (activity, initiative, independence, determination, ambition, desire for knowledge, professionalism) were traced. The percentage contribution of each value, motivating and determining the formation of personality was determined. Tables and histograms were built for each question of the questionnaire.

The study was based on personal, activity, inclusive and subjective approaches. General methodological principles of research included the principles of determinism, social determination of personality, and development. Methods of research included the analysis of literary sources, questionnaires, overt observation, survey, methods of statistical data processing.

\section{Result}

Theoretical analysis of the ISI RAS, VCIOM, ROMIR, RSIS\&NP research from 1992-2005 showed that trends in the development of views, perceptions, and values of Soviet and postSoviet society were generally described. Unfortunately, the studies did not pay enough attention to the spiritual and moral aspects of personal development. The main result for our study was the conclusion that by the beginning of the XXI century there was a tendency to a certain increase in the overall spiritual and moral state of the Russian's personality.

The VCIOM research shows that by 2005 the role of personal qualities such as neatness, mercy, victimhood, etc. had decreased. For example, the evaluation of victimhood decreased from $11.8 \%$ to $9.7 \%$, i.e. to the level of practically insignificant value. However, the role of humanity significantly increased from $50.7 \%$ to $56.9 \%$. The role of diligence has also increased from $67.5 \%$ to $72.2 \%$, probably, in the minds of individuals, it was associated with success. The importance of the church remained virtually unchanged, that is, religion occupied a solid position in the minds of people.

2007,2009 pieces of research were aimed at studying values systems, spiritual and moral values, values that contribute to the development of personality. The results showed the dynamics of the process, in the period of two years, in Penza. For details and completeness of the values' development picture let us compare the results of the surveys in 2007 and 2009. (Figure 1).

According to the analysis of the results obtained, the following conclusions can be drawn: schoolchildren attached great importance to vital and social values. This can be possibly explained by the increasing role of economic factors in the country during this period. An increase in the importance of moral values compared to 2007 and a decrease in the importance of religious values was recorded.

All of the value importance indicators for students have increased. This indicates both a "spiritual increase" in the moral character of young people and an increase of vital and social values importance.

Working youth provides a more mature and conscious assessment of values. Moreover, there is a notable increase in the importance of religious values, which can be explained by the period when the church has stepped up its politics and its increasing role in society, as well as by young people's desire for traditional culture. The importance of political values demonstrates the desire for awareness and knowledge of politics. 


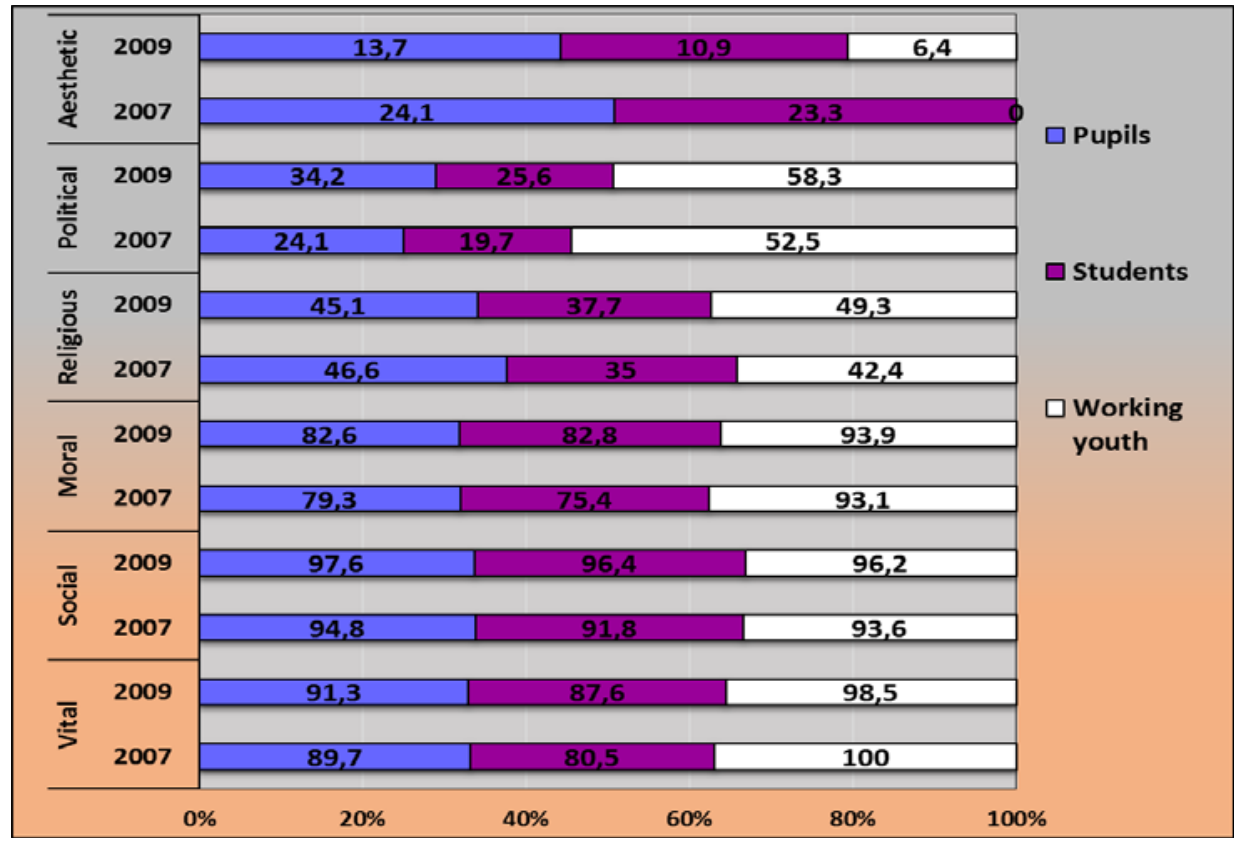

Fig. 1. Graphical change in the importance of value systems according to the results of surveys in 2007 and 2009 , in $\%$.

Despite this, when assessing the respondents' specific spiritual and moral values in the questionnaire, a rather pessimistic pattern is observed. The dynamic development of positive trait indicators decreases sharply (Figure 2).

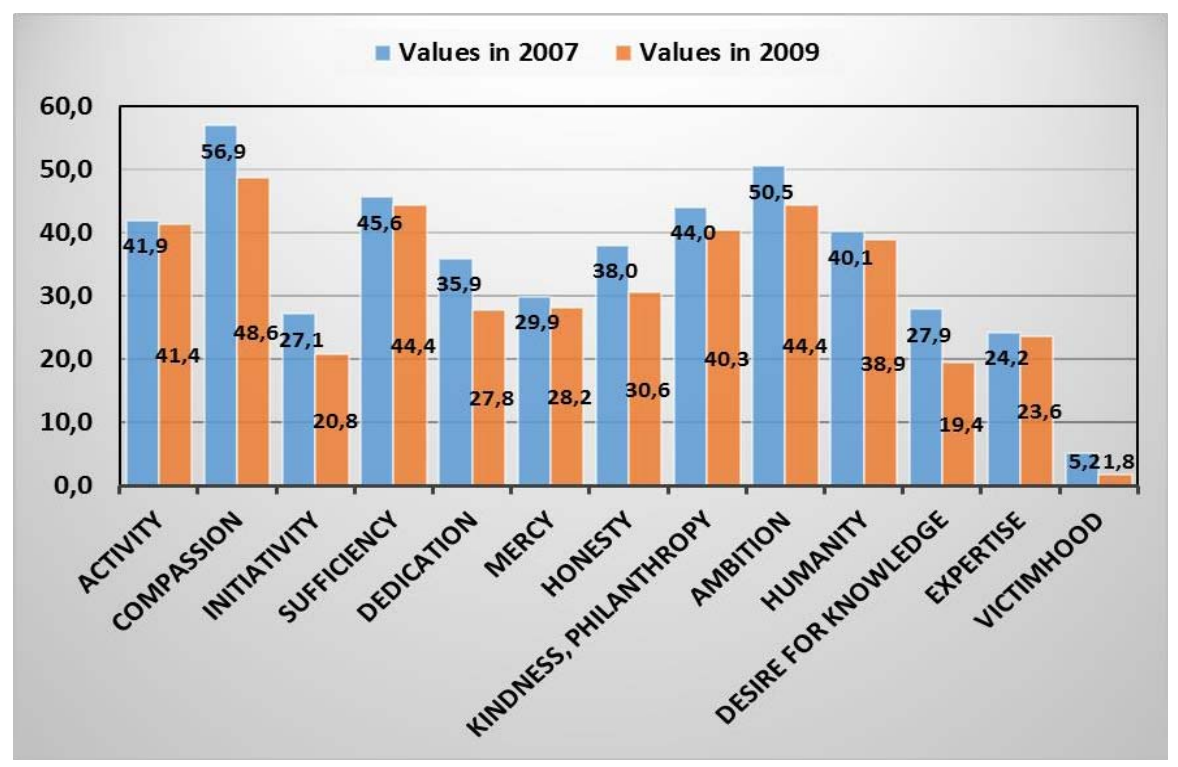

Fig. 2. Respondents' values in 2007 and 2009, in \%.

In general, the study results indicate a certain lack of confidence in the future among young people. It can be assumed that in connection with this, spiritual qualities (responsiveness, honesty, victimhood, desire for knowledge) are decreasing. Leadership, 
"combative" qualities that contribute to realization, such as initiative, determination, ambition, also give up their positions. All this signals a certain decline in the spiritual state of young people.

The results of studies conducted in 2010 in the Volga, Central, and Southern Federal Districts in four age groups of young people (14-17 years, 18-21 years, 22-25 years, 26-29 years) are summarized in Figure 3.

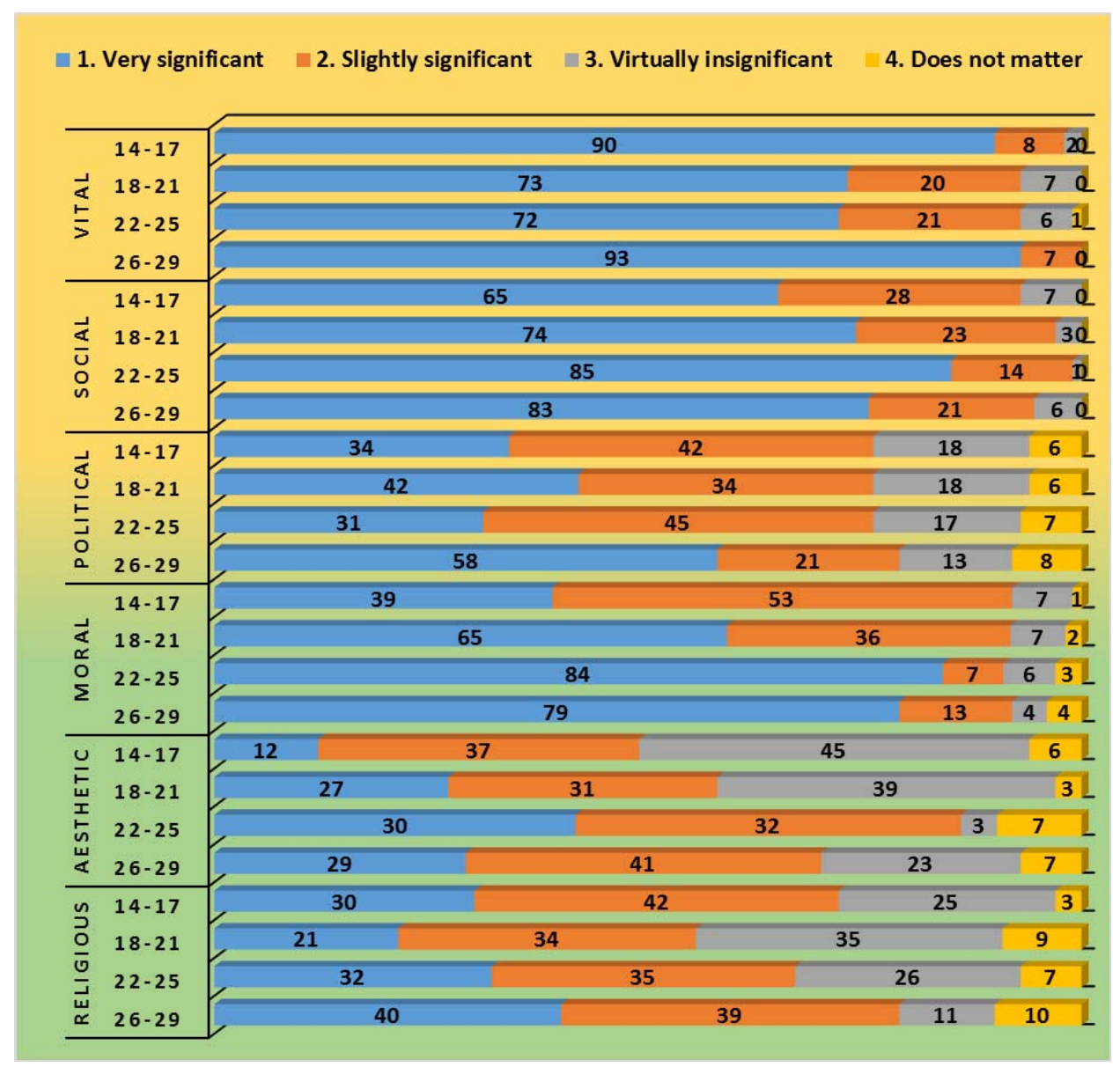

Fig. 3. Significance of Value Systems 2010, in \% 1. Very significant; 2. Slightly significant; 3. Virtually insignificant; 4. Does not matter.

Analysis of the results shows that vital (from $72 \%$ to $90 \%$ ) and social (from $65 \%$ to $85 \%$ ) values are of high priority for each age group. Vital values are related to the value of life and include life sustaining, health, as well as children, family, ecology, etc. Social orientation and expectations raise the importance of social values particularly during the period of social realization, which can be seen in the groups of young people $22-29$ years old $(83-85 \%)$. Political values are most expressed in the group of 26-29 years (58\%), as a conscious concern for their country and its and their future. A positive aspect of our study is the degree of moral values (53\%-84\%), their comprehension with the acquisition of life experience. Aesthetic values and religious values have the smallest percentage. 
Table 1. Significance of spiritual and moral values in modern life, 2010, in $\%$.

\begin{tabular}{|c|c|c|c|c|c|c|c|c|c|c|c|c|c|c|c|c|}
\hline Values & \multicolumn{4}{|c|}{ Very significant } & \multicolumn{4}{|c|}{ Slightly significant } & \multicolumn{4}{|c|}{ Virtually insignificant } & \multicolumn{4}{|c|}{ Does not matter } \\
\hline Age groups & $\frac{\bar{z}}{ \pm}$ & $\overrightarrow{\widetilde{N}}$ & 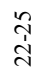 & $\begin{array}{l}\text { సे } \\
\text { ஸे }\end{array}$ & $\stackrel{\bar{I}}{ \pm}$ & $\underset{\mathscr{\sigma}}{\mathscr{\infty}}$ & 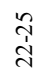 & స్ & $\stackrel{I}{ \pm}$ & 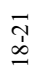 & 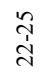 & $\begin{array}{l}\text { సे } \\
\text { ஸे }\end{array}$ & $\frac{\bar{g}}{ \pm}$ & $\begin{array}{l}\vec{T} \\
\underset{\infty}{-}\end{array}$ & 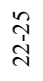 & $\begin{array}{l}\text { సे } \\
\text { ஸे }\end{array}$ \\
\hline Humanity & 55 & 48 & 60 & 50 & 29 & 39 & 32 & 31 & 5 & 13 & 5 & 17 & 1 & 0 & 2 & 1 \\
\hline Victimhood & 22 & 11 & 10 & 19 & 44 & 50 & 41 & 49 & 24 & 24 & 45 & 25 & 10 & 25 & 4 & 7 \\
\hline Mercy & 48 & 38 & 55 & 52 & 41 & 48 & 40 & 47 & 11 & 10 & 5 & 1 & 0 & 4 & 0 & 0 \\
\hline Love & 71 & 75 & 86 & 91 & 22 & 20 & 14 & 9 & 6 & 3 & 0 & 0 & 1 & 2 & 0 & 0 \\
\hline Kindness & 58 & 53 & 84 & 88 & 25 & 28 & 12 & 10 & 13 & 17 & 4 & 2 & 4 & 2 & 0 & 0 \\
\hline Compassion & 70 & 81 & 62 & 52 & 22 & 19 & 27 & 38 & 8 & 0 & 10 & 9 & 0 & 0 & 1 & 1 \\
\hline Cognition & 55 & 70 & 71 & 65 & 39 & 24 & 23 & 27 & 6 & 4 & 5 & 5 & 0 & 2 & 1 & 3 \\
\hline $\begin{array}{l}\text { Natural } \\
\text { beauty }\end{array}$ & 14 & 23 & 12 & 24 & 61 & 46 & 55 & 61 & 19 & 27 & 30 & 10 & 6 & 4 & 7 & 5 \\
\hline Humility & 11 & 8 & 9 & 21 & 27 & 22 & 21 & 17 & 25 & 30 & 31 & 14 & 37 & 40 & 39 & 48 \\
\hline Patience & 47 & 39 & 40 & 47 & 42 & 51 & 42 & 43 & 11 & 9 & 18 & 10 & 0 & 1 & 0 & 0 \\
\hline Justice & 59 & 39 & 60 & 69 & 31 & 41 & 20 & 30 & 8 & 18 & 9 & 1 & 2 & 2 & 1 & 0 \\
\hline Honesty & 72 & 68 & 79 & 72 & 17 & 22 & 20 & 17 & 11 & 10 & 1 & 11 & 0 & 0 & 0 & 0 \\
\hline $\begin{array}{l}\text { Happiness of } \\
\text { others }\end{array}$ & 45 & 35 & 55 & 56 & 31 & 52 & 42 & 40 & 24 & 13 & 3 & 4 & 0 & 0 & 0 & 0 \\
\hline Generosity & 11 & 8 & 42 & 31 & 21 & 23 & 18 & 11 & 30 & 21 & 14 & 34 & 38 & 46 & 26 & 24 \\
\hline Unselfishness & 17 & 19 & 55 & 27 & 26 & 28 & 13 & 6 & 45 & 40 & 32 & 25 & 12 & 13 & 0 & 32 \\
\hline Compliance & 13 & 7 & 18 & 23 & 29 & 33 & 43 & 19 & 41 & 36 & 25 & 31 & 17 & 24 & 14 & 27 \\
\hline
\end{tabular}

The study results of the respondents' individual values (Table 1) show that the following values at ages $14-17$ are very significant (over 50\%): honesty (72\%), love (71\%), compassion $(70 \%)$, justice (59\%), kindness (58\%), cognition and humanity (55\%). Ages 18-21: love (75\%), compassion (81\%), cognition (70\%), honesty (68\%), kindness (53\%). Ages $18-21$ : love $(86 \%)$, kindness $(84 \%)$, honesty $(79 \%)$, cognition $(71 \%)$, compassion $(62 \%)$, justice and humanity $(60 \%)$, mercy and happiness of others $(55 \%)$. Ages $18-21$ : love $(91 \%)$, kindness (88), honesty $(72 \%)$, justice $(69 \%)$, cognition $(65 \%)$, happiness of others $(56 \%)$, mercy and compassion $(52 \%)$, humanity $(50 \%)$.

Regardless of age, respondents ranked as very significant the same spiritual and moral values, specifically love, kindness, compassion, cognition, honesty, humanity, mercy, justice, patience, the happiness of others. Victimhood and unselfishness were considered significant. Humility, generosity, unselfishness, and compliance were chosen to a lesser extent.

For a more complete picture of the dynamics of young people's spiritual and moral values development and formation, we will present the results of the 2019 study in the Volga, Central and Southern Federal Districts, conducted in 4 age groups of young people (14-17 years, 18-21 years, 22-25 years, 26-29 years). Values indicators are compared according to the 2010 and 2019 results. 


\begin{tabular}{|c|c|c|c|c|}
\hline \multicolumn{2}{|c|}{ 1. Very significant } & 2. Slightly significant & 3. Virtually insignificant & \multirow{2}{*}{ 4. Does not matter } \\
\hline & $14-17$ & & 93 & \\
\hline $\overrightarrow{4}$ & $18-21$ & & 81 & 18 \\
\hline 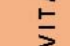 & $22-25$ & & 80 & 19 \\
\hline & $26-29$ & & 90 & 100 \\
\hline \multirow{4}{*}{$\begin{array}{l}\text { d) } \\
\bar{u} \\
\text { O } \\
\text { n }\end{array}$} & $14-17$ & 63 & & 101 \\
\hline & $18-21$ & & 83 & 17 \\
\hline & $22-25$ & & 96 & 40 \\
\hline & $26-29$ & & 96 & 40 \\
\hline \multirow{4}{*}{$\begin{array}{l}\frac{1}{6} \\
\frac{u}{E} \\
\frac{\vec{E}}{0} \\
0\end{array}$} & 14-17 & 35 & 36 & 9 \\
\hline & $18-21$ & 56 & 28 & 15 \\
\hline & $22-25$ & 45 & 36 & 18 \\
\hline & $26-29$ & & 78 & 22 \\
\hline \multirow{4}{*}{$\begin{array}{l}\text { \& } \\
\text { 文 } \\
0 \\
\Sigma\end{array}$} & 14-17 & 35 & 28 & 20 \\
\hline & $18-21$ & 29 & 41 & 15 \\
\hline & $22-25$ & 56 & & 60 \\
\hline & $26-29$ & & 91 & 8 1 \\
\hline \multirow{4}{*}{ 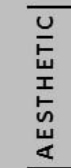 } & 14-17 & 18 & 37 & 30 \\
\hline & $18-21$ & 25 & 41 & 23 \\
\hline & $22-25$ & 39 & 38 & \begin{tabular}{l|l}
13 & 10
\end{tabular} \\
\hline & $26-29$ & 31 & 38 & $18 \quad 13$ \\
\hline \multirow{4}{*}{ 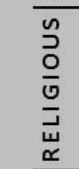 } & 14-17 & 25 & 32 & 20 \\
\hline & $18-21$ & 32 & 36 & 18 \\
\hline & $22-25$ & 33 & 38 & 19 \\
\hline & $26-29$ & 53 & 28 & $4 \quad 15$ \\
\hline
\end{tabular}

Fig. 4. Significance of Value Systems, 2019, in \%. Very significant; 2. Slightly significant; 3. Virtually insignificant; 4. Does not matter.

According to the results of the value systems significance study (Figure 4), we can note the following, that the most relevant, as in the 2010 study, are the vital and social value systems. Exceptions are the importance of social values for 14-17 years old, the numbers dropped from $65 \%$ to $63 \%$ (very significant) and from $28 \%$ to $26 \%$ (slightly significant). Political values significance increased for 18 to 29 age groups. The moral values significance decreased for ages $14-17$ from $39 \%$ to $35 \%$ and for ages $22-25$ from $84 \%$ to $56 \%$ (very significant), but increased from $7 \%$ to $38 \%$ (slightly significant). The aesthetic values' significance decreased overall for ages 14-17, 18-21, remained virtually unchanged for ages $26-29$ but increased for ages $22-25$ from $30 \%$ to $39 \%$ (very significant) and $32 \%$ to $38 \%$ (slightly significant). Religious values decreased only for 14-17-year-olds, for other groups of respondents this indicator increased as significant.

The results show that the rate of certain values (Table 2), compared with 2010, has changed. Thus, among the very significant (over 50\%) at the age of 14-17 years are honesty $(66 \%$, instead of $72 \%$ in 2010$)$, love $(77 \%$, instead of $71 \%)$, compassion $(65 \%$, instead of $70 \%$ ), justice $(59 \%$, same as in 2010$)$, kindness $(61 \%$, instead of $58 \%)$, humanity $(51 \%$, instead of 55\%). Compared to 2010, mercy (56\%) was added, but cognition decreased $(45 \%$, instead of $55 \%)$. Ages $18-21$ : love (76\%, instead of $75 \%)$, compassion (77\%, instead of $81 \%)$, cognition $(68 \%$, instead of $70 \%)$, honesty $(59 \%$, instead of $68 \%)$, kindness $(59 \%$, instead of $53 \%$ ). Ages $22-25$ : love $(66 \%$, instead of $86 \%)$, kindness $(77 \%$, instead of $84 \%)$, honesty 
(71\%, instead of $79 \%)$, compassion ( $69 \%$, instead of $62 \%)$, justice $(64 \%$, instead of $60 \%)$, mercy $(53 \%$, instead of $55 \%)$. The values of cognition $(47 \%$, instead of $71 \%)$ and humanity $(49 \%$, instead of $71 \%)$, the happiness of others $(53 \%$, instead of $71 \%)$ decreased significantly. The values of patience (55\% instead of $40 \%)$ and natural beauty ( $58 \%$ instead of $12 \%$ ) appeared. Ages $26-29$ : love (70\%, instead of $91 \%)$, kindness $(76 \%$, instead of $88 \%)$, honesty $(70 \%$, instead of $72 \%)$, justice $(62 \%$, instead of $69 \%)$, happiness of others $(53 \%$, instead of $56 \%)$, mercy and compassion (55\%, instead of 52\%), humanity $(60 \%$, instead of $50 \%)$. Cognition came in lower $(55 \%$, instead of $65 \%)$. Values of patience $(57 \%$, instead of $47 \%)$ and natural beauty $(59 \%$, instead of $24 \%)$ became higher.

Table 2. Significance of spiritual and moral values in modern life, 2019, in \%.

\begin{tabular}{|c|c|c|c|c|c|c|c|c|c|c|c|c|c|c|c|c|}
\hline Values & \multicolumn{4}{|c|}{ Very significant } & \multicolumn{4}{|c|}{ Slightly significant } & \multicolumn{4}{|c|}{ Virtually insignifcant } & \multicolumn{4}{|c|}{ Does not matter } \\
\hline Age groups & $\stackrel{\Xi}{ \pm}$ & $\begin{array}{l}\overrightarrow{\hat{T}} \\
\infty\end{array}$ & $\begin{array}{l}\stackrel{2}{N} \\
\stackrel{\sim}{N}\end{array}$ & શે & $\frac{\bar{J}}{\dot{J}}$ & $\begin{array}{l}\overrightarrow{\widehat{T}} \\
\infty \\
-\end{array}$ & $\begin{array}{l}\stackrel{n}{1} \\
\text { तิ }\end{array}$ & సे & I & $\begin{array}{l}\vec{T} \\
\infty \\
\infty\end{array}$ & $\begin{array}{l}\stackrel{\sim}{N} \\
\text { N }\end{array}$ & సે & İ & $\overrightarrow{\widetilde{N}}$ & $\begin{array}{l}\stackrel{\sim}{1} \\
\stackrel{\sim}{N}\end{array}$ & సे \\
\hline Humanity & 51 & 40 & 49 & 60 & 34 & 39 & 40 & 23 & 10 & 11 & 7 & $\overline{9}$ & 5 & 10 & 4 & 8 \\
\hline Victimhood & 28 & 13 & 18 & 29 & 44 & 48 & 38 & 42 & 24 & 25 & 29 & 24 & 10 & 14 & 15 & 5 \\
\hline Mercy & 56 & 42 & 53 & 55 & 41 & 45 & 46 & 45 & 3 & 7 & 1 & 0 & 0 & 6 & 0 & 0 \\
\hline Love & 77 & 76 & 66 & 70 & 19 & 22 & 33 & 30 & 3 & 1 & 1 & 0 & 1 & 1 & 0 & 0 \\
\hline Kindness & 61 & 59 & 77 & 76 & 27 & 29 & 11 & 18 & 9 & 7 & 12 & 3 & 3 & 5 & 0 & 3 \\
\hline Compassion & 65 & 77 & 69 & 55 & 32 & 23 & 30 & 29 & 3 & 0 & 1 & 16 & 0 & 0 & 0 & 0 \\
\hline Cognition & 45 & 68 & 47 & 55 & 37 & 28 & 41 & 39 & 6 & 4 & 7 & 5 & 0 & $\overline{0}$ & 5 & 1 \\
\hline $\begin{array}{r}\text { Natural } \\
\text { beauty }\end{array}$ & 24 & 31 & 58 & 59 & 54 & 45 & 33 & 40 & 19 & 21 & 6 & 1 & 3 & 3 & 1 & 0 \\
\hline Humility & 9 & 11 & 16 & 20 & 27 & 25 & 27 & 9 & 26 & 29 & 33 & 34 & 38 & 35 & 24 & 37 \\
\hline Patience & 43 & 41 & 55 & 57 & 43 & 49 & 30 & 35 & 13 & 9 & 11 & 7 & 1 & 1 & 4 & 1 \\
\hline Justice & 59 & 48 & 64 & 62 & 31 & 33 & 28 & 30 & 9 & 15 & 7 & 5 & 1 & 4 & 1 & 3 \\
\hline Honesty & 66 & 59 & 71 & 70 & 19 & 28 & 27 & 29 & 14 & 11 & 2 & 1 & 1 & 2 & 0 & 0 \\
\hline $\begin{array}{r}\text { Happiness of } \\
\text { others }\end{array}$ & 35 & 37 & 48 & 53 & 38 & 42 & 44 & 30 & 26 & 21 & 8 & 17 & 1 & $\overline{0}$ & 0 & 0 \\
\hline Generosity & 17 & 13 & 45 & 44 & 19 & 25 & 19 & 17 & 30 & 26 & 19 & 24 & 44 & 36 & 17 & 15 \\
\hline Unselfishness & 19 & 21 & 49 & 33 & 15 & 23 & 6 & 9 & 55 & 32 & 44 & 30 & 11 & 14 & 1 & 28 \\
\hline Compliance & 15 & 21 & 23 & 27 & 33 & 30 & 35 & 22 & 39 & 38 & 30 & 40 & 23 & 11 & 12 & 11 \\
\hline
\end{tabular}

Respondents highlighted values similar to those in 2010 as very significant, some of them have become slightly higher of significance, some lower. So the value of cognition decreased in each age: $14-17$ years old ( $45 \%$, instead of 55\%), $22-25$ years old $(47 \%$, instead of $71 \%)$, $26-29$ years old $(55 \%$, instead of $65 \%)$. At ages $22-25$, the value of humanity ( $49 \%$, instead of $71 \%$ ), happiness of others (53\%, instead of 71\%) decreased significantly. Ages $22-25$ and 26-29 showed values of patience (55\% instead of $40 \%$ and $57 \%$ instead of $47 \%$ ) and the beauty of nature (58\% instead of $12 \%$ and 59 instead of $24 \%$ ). At ages $14-17$, mercy was added $(56 \%)$.

\section{Discussion}

Modern socio-economic conditions bring changes in the system of values. Values of life sustaining - vital and social - come to the picture. They become decisive in the goal-setting system of the individual. Increasing the level and quality of life, welfare, and health, security 
for themselves and their families determine the plans and dreams of the individuals at each of the considered age groups. Each of the vital values is associated with the entities of the external world, in which the implementation of the personality takes place. The conditions of society determine the trends of actual achievements and form specific directions in which the implementation of its life ideals and goals is possible. They also determine the political interest, especially of working youth, who worry about their country and their future and therefore seek consciousness and awareness in the sphere of numerous political changes and transformations.

The results of research on moral and religious value systems are of particular interest for our study. Since the beginning of the XXI century, various studies have emphasized the increasing importance of moral values. They are the basic concepts of moral consciousness and determine the norms of behavior in society, indicating the way of social ideal development and attainment. In Russia, this ideal has always been spirituality, practically manifested through values that are pleasant to the soul, and, at the same time, useful for society - good, love, mercy, victimhood, etc. Historically, spirituality was expressed through religious values, which, although not significantly, but in increased indicators, was manifested in the course of the study.

The desire of young people to traditional culture and spiritual and moral values was noted during the study of certain values. Values, as fundamental mental formations, contain ideas about the ideal models of behavior and goals for the respondents. This is what gives stability to the out-of-balance social environment in crises. In this regard, the respondents have a fairly stable picture of spiritual and moral values integrity and an increase in the number of indicators. The mental base that protects the personality in times of crisis and creates development opportunities has manifested itself through the values.

These provisions obtained in the course of the study are confirmed by various authors' researches. Thus, V.V. Babashkin [2] points out that Russia, closely looking at the basic values of the West and the East, should not forget their own, collective values. You can dream of either alternative, but it is necessary to know that in any case something very Russian is realized. Each state claims its way and it is impossible to find some common standard. The idealization of what is considered the norm is present in each case. The author cites as an example a letter from V.I. Zasulich to K. Marx on the possibility of Marxism's application in Russia. The answer received was: "No way". "Capital" is based on English materials and is suitable for England, as well as for several countries comparable with it, but Russia is incomparable. It has a different basis of social organization, the community, which the Russian revolutionaries ought to study, guarding against the rude political interference. Having studied several sociological studies, V. V.Babashkin states that over the past decades, a shift in the frame of the masses' mind, fixed by sociologists, has taken place in Russia, namely, a reorientation from the depressing present to a retrospectively embellished traditional past.

As L. Sagiv, S. Roccas, J. Cieciuch, S.H. Schwartz [3] say this happens because people always express the values of their culture and achieve the underlying goals of such values. Values are always personal and therefore reflect internal preferences and choices. Although little is known about the origin of values, it is clear that the fact they are shaped by a combination of genetic heritage and the influence of different social environments determines behavior.

This is also confirmed by the research of E. Y. Pochtareva [4], which specifies that the integrated holistic personality contains specific structures of the internal and external world as a condition for its development. Values and motives, determining the internal guidelines of the personality, are revealed into space, conditioning the personal motives regulation of the mentality and self-fulfillment of life activity. However, the author notes, the inclusion of the personality in different value- and motive-forming contexts creates the need to identify 
the dominant relationships that determine the value- and motive sphere and define the formation of motives and values. In this regard, the author goes to the values of individualism and collectivism and notes their ironic compatibility.

Special attention should be paid to this. The study of the issue allows us to claim that individualism contains not only the acquisition of benefits for oneself, noted in numerous studies but also individual implementation in society, the manifestation, and assertion of one's uniqueness. By connecting it to spiritual and moral values, spiritual realization can be strengthened, manifested in the distinctive peculiarity of the individual mentality. In this case, individualism will acquire another, higher level of comprehension of its manifestation and direction of realization. M.S. Yanitsky's researches [5] confirm that value systems defining social behavior bear differences expressed in the level of life comprehension, self-fulfillment, regulation of social behavior.

We can assume that spiritual and moral values (love, kindness, honesty, compassion, humanity, mercy, etc.) are the basis of any culture, as a manifestation of the highest stage of self-realization. This is also confirmed by the research of several authors. Thus, Schwartz, S. H. [6] writes that there are basic values, distinguished by a universal dynamic structure, which are unconditionally recognized in any culture, determining special decisions and behavior through mechanisms. However, the distinction of values in terms of importance is carried out by the people themselves in each culture. Therefore, specific value priorities correlate with numerous behaviors and attitudes. As a result, values can even compete and influence people's behavior and attitudes, so compromises are necessary.

V. Ponizovskiy, L. Grigoryan, U. Kühnen, K. Boehnke [7] also describe the presence of basic values, their general structure, and general patterns in respect to values and attitudes determined by beliefs. According to the authors, it is the social structure that determines the direction of the motivational force of values and specifies patterns of behavior. A person's set of preferred values depends on the influences exercised on the personality during socialization.

The competition between values and social norms noted by the authors is interesting. Values, as fundamental general principles, apply to any situation, while societal norms apply only to a specific situation. They note that there is a conflict of "openness to change vs. integrity," that is, between openness to change and new experience and order, control, and restraint.

Studies of O. Y. Glukhova [8] also draw attention to the existence of metanorm (values: honesty, loyalty, mutual assistance, etc.), orientation on which can provide society a peaceful coexistence. The main thing, in this case, is reliance on common worldview bases, common laws of existence, and mutual influence of man and the surrounding world. The author makes an optimistic conclusion that the modern world is moving to the products of meaning-making through cognitive technologies and mental structures.

The existence of universals in the values' content and structure was emphasized by G.R. Maio [9]. Considering values through mentality, he defined values as mental representations, reflecting motivational tension and acting on a systemic level, including the abstract level and the level of fulfillment.

The matter of basic, fundamental values and motives for all peoples correlates with the integrity of each civilization as a unique distinctiveness, part of a single whole. In another study, O. Y. Glukhova [10] associates values and motives with cultural identity and civilizational identity, which must be preserved. She raises the question of Russia's refusal to copy Western cultural patterns that transform the life values of other nations. And emphasizes that in the era of global dialogue of cultures, there should not be an increasing tendency to preserve one single identity, a Western one, for example. This will lead to the gradual withdrawal of other types of identities from the world stage, as cultural values and patterns 
will begin to spread without reference to the civilization's inorganic body, i.e. to the objects of the material world.

The fact that civilization is a projective perspective of the view is also noted by N.B. Afanasov [11]. It is the cultural complexity of the modern world that leads to a significant loss of clarity in the meanings of personality concepts. V.M. Mezhuev [12] emphasizes that any civilization implies the existence of borders separating humanity in the present and the past, the cultural identity of people. Their separate existence has remained unchanged for centuries and there is no such power in the world to merge these worlds.

In this regard, N. Eremina [13] shows the need to acquire a national identity within the framework of the world culture and the globalized world in the course of the historiosophic comprehension of the existence of the country. L.S. Perepelkin [14] draws attention to what unites all the peoples of the country, namely the common historical memory formed traditionally as a result of territorial expansion and high consolidation of ethnic groups, and peculiarities of history. A special type of civilization emphasizes a unique socio-historical destiny, an original stereotype of behavior, and a certain tradition of relations with neighbors.

According to A.S. Sokolov and N.A. Stepanov [15], the appeal to the problems of civilizational identity, as a rule, occurs during the periods of complex, critical development of the subject when searching for the right vector of further way and correlating itself with the general context of world development. Options for development: searching for "one's" civilization and understanding one's place in the general civilizational context, or discovering one's civilizational essence and justifying one's type of civilization.

The authors emphasize that Russia, not having found a place in Western civilization, follows this path. It is important to live in its civilizational identity formed by a set of objective processes occurring in the depths of society and connected by social "staples" with the "generic", the deepest property of the subject, fixed in the generations and "protected" from particular and insignificant socio-cultural transformations. Deeper identity has little to do with the superstructure that emerges from dealing with the world of ideas.

By reconstructing the projects of Russian civilization proposed by Russian and foreign philosophers of the 19th and 20th centuries, Y.M. Reznik [16] has brought them closer to understanding the civilizational realities of modern Russia. He noted that most philosophers see Russia as a transcendental (the presence of "higher values" or "divine mission", etc.), human-dimensional (correspondence to human nature or the national character of society), intellectually mobile (the priority of science and education development), politically and economically stable civilization, where a reasonable balance of man and the socio-natural environment comes first.

The author highlighted projects based on the idea of the civilization's spiritual organization of life (H. Hegel, A. Schweitzer, and S. Huntington, etc.). So, according to Hegel, civilization should pass the stage of objective spirit development and be embodied in its moral idea, to revive the moral foundations of life, overcoming the contradiction between egoistic subjectivity, on the one hand, and the objective need to integrate different civilizational projects. According to A. Schweitzer, to develop the capacity for self-denial and self-improvement through the love of one's native land. According to S. Huntington, to complete the civilizational project by uniting the entire orthodox world.

Y.M. Reznik notes that Russia has: a great culture, a stable social structure, and the moral and creative properties of people. Russia takes into account the diversity of cultures, embedded in a common system - civilization. The idea of all-humanity is related to the identification of each subject with a common cause, ensuring "the unity of multiplicity." But still, the author concludes that to implement such a project in the modern world, it is necessary to pay attention to the virtues of Western civilization, which should be borrowed.

For example, as noted by I. E. Sokolovskaya and I. V. Volochkov [17], the desire of the West for hedonism and freedom can be transformed on the Russian platform in the form of 
motivation for self-development, and the development of spiritual values will help drug addicts to reduce personal aggressiveness, anxiety and increase adaptive capabilities to society [18].

\section{Conclusions}

The analysis of the results allows us to draw the following conclusions: vital and social values are relevant for all respondents, schoolchildren, students, and working youth. These choices are influenced by modern socioeconomic factors. Spiritual and moral values, emphasizing the desire of young people for traditional culture, reliance on the mental base that protects the personality in times of crisis, remain in their entirety, with a decrease in several indicators, but with an increase in others.

Despite this, modern socio-economic conditions bring changes to the system of values. Therefore, numerous studies emphasize the need to take into account both the existence of basic fundamental values and motives, which are the basis of any culture and specific ones, characteristic for a particular civilization. Since each state has its way of development, being part of the multiple integrity while maintaining uniqueness in the unity. Russia is an example of taking into account the diversity of cultures of different peoples built into a common system - civilization. An example of combining the common and the special based on common basic spiritual and moral values.

In this regard, it becomes relevant to study the processes of spiritual and moral values' transformation as the basis of the identity of the people and its development; consideration of traditional values' essential stability and independence in the radically changing conditions of modernity; changing the structures of Russians' consciousness, as a result of the influence on the world of ideas, which are often poorly connected with the core identity; spiritual and moral values' study as the best internal condition for adaptation to the external, transformational conditions of life.

\section{References}

1. D.B. Kazantseva, Transformational Processes of the Spiritual Potential of a Personality (Monograph. Penza: PSU Publishing House. 2010)

2. V.V. Babashkin, Peculiarities of the national road, or what's the big time for a Russian, World of Russia 27, 4, 163-175 (2018) DOI: 10.17323/1811-038X-2018-27-4-163-175.

3. L. Sagiv, S. Roccas, J. Cieciuch, S.H. Schwartz, Personal values in human life, Nature Human Behaviour 1(9), 630-639 (2017) DOI: 10.1038/s41562-017-0185-3

4. E.Y. Pochtareva, The value-motive sphere of the personality: essence, determinants, and mechanisms of development, Perm University Bulletin 4, 563-575 (2017) DOI:10.17072/2078-7898/2017-4-563-575

5. M.S. Yanitsky, System of Value Orientations of Personality and Social Communities: Structural and Dynamic Model and its Application in Psychological Research and Psychological Practice, Bulletin of Kemerovo State University 22(1), 194-206 (2020) DOI:10.21603/2078-8975-2020-22-1-194-206

6. S.H. Schwartz, Basic individual values: Sources and consequences, In D. Sander and T. Brosch (Eds.), Handbook of value. Oxford, UK: Oxford University Press 63-84 (2015)

7. V. Ponizovskiy, L. Grigoryan, U. Kühnen, K. Boehnke, Social Construction of the Value-Behavior Relation, Front. Psychol 10, 934 (2019) Published online 2019 May 1. doi: 10.3389/fpsyg.2019.00934 
8. O.Y. Glukhova, The worldview motives of human beings and their significance for the construction of the modern scientific picture of the world, Social theory issues X, 53-58 (2018) DOI: 10.30936/2227-7951-2018-10-53-58

9. G.R. Maio, Mental representations of social values, Advances in experimental social psychology 42, 1-43 (2010) Academic Press. https://doi.org/10.1016/S00652601(10)42001-8

10. O.Y. Glukhova, Western-Eastern cultural dialogue. The Problem of Metacultural Identity, Social theory issues XI (2019) DOI: 10.30936/2227-7951-2019-11-41-56

11. N.B. Afanasov, Toward a Civilization Project within the context of late globalization, Social theory issues XI, 28-40 (2019) DOI: 10.30936/2227-7951-2019-11-28-40

12. V.M. Mezhuev, Civilization or civilizations? (to the debate over the concept of civilization), Znanie. Ponimanie. Umenie 2, 40-52 (2016) DOI: 10.17805/zpu.2016.2.4

13. N. Eremina, Advent of a New Civilizational Project: Eurasia in - U.S. out? Journal of Eurasian Studies 7, 162-177 (2016) https://doi.org/10.1016/j.euras.2016.02.001

14. L.S. Perepelkin, Russia and its civilizational future: winning positions (Anthropologist's View), Social theory issues XII, 172-186 (2020) DOI: 10.30936/2227-7951-2020-12172-186

15. A.S. Sokolov, N.A. Stepanov, Interdisciplinarity of historical research as a condition for the search for the civilizational identity of Russia, Social theory issues XII, 276-284 (2020) DOI: 10.30936/2227-7951-2020-12-276-284

16. Y.M. Reznik, Visions of Russia's civilizational future: individual projects and possibilities of their integration, Social theory issues XII, 10-25 (2020) DOI: 10.30936/2227-7951-2020-12-10-120

17. I.E. Sokolovskaya, I.V. Volochkova, Socio-psychological aspects of the development of super-needs of a person by the "trouble-hacking" methodology (psychological analysis of the methodology), Azimuth of scientific research: pedagogy and psychology 8, 4 (29), 363-366 (2019) DOI: 10.26140/anip-2019-0804-0099

18. I.E. Sokolovskaya, I.P. Kutyakova, Value orientations as a factor of maladaptive behavior of drug addicts, Scientific notes of the Russian State Social University 18, 2 (151), 49-59 (2019) DOI: 10.17922/2071-5323-2019-18-2-49-59 